\title{
Network of Polyaniline Nanotubes for Wastewater Treatment and Oil/Water Separation
}

\author{
Sanjoy Mondal, Utpal Rana, Puspendu Das and Sudip Malik* \\ School of Applied and Interdisciplinary Sciences (Formerly Polymer Science Unit), Indian \\ Association for the Cultivation of Science, 2A \& 2B Raja S.C. Mullick Road., Jadavpur, \\ Kolkata - 700032, India. \\ E-mail ID: psusm2@iacs.res.in
}

\section{Table of content}

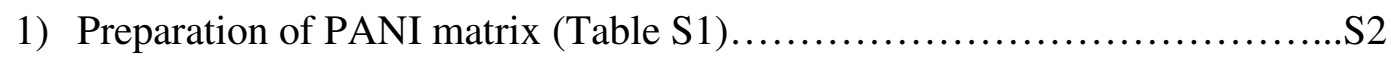

2) Synthesis of $\mathrm{HCl}$ doped PANI....................................... 3

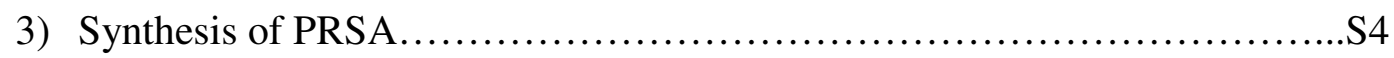

4) TGA study of B4CAP matrix............................................ 5

5) Dye adsorption capacity of Different PANI matrix............................S6

6) FESEM and TEM images of B4CAP matrix..............................

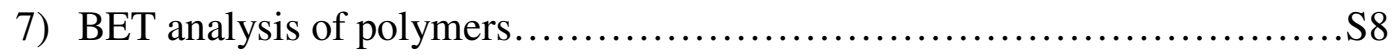

8) UV-Vis spectra of MB and CV dye with different times......................S9

9) Dye Adsorption mechanism on PANI surface..........................S10

10) Effect of $\mathrm{pH}$ on dye adsorption...................................... 11

11) Morphology of B4CAP fiber before and after adsorption.............................S12

12) Table S2: Previous work............................................... 13

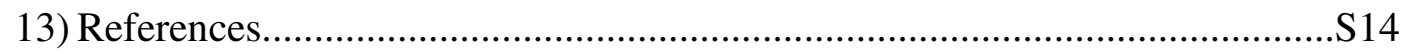


Table S1: Synthesis of PANI matrix with different dopant acids

\begin{tabular}{|c|c|c|c|c|c|}
\hline \multirow[t]{2}{*}{ Nanostructure } & \multicolumn{2}{|c|}{ Dopant Acids } & \multirow{2}{*}{$\begin{array}{c}\text { APS } \\
(\mathbf{m m o l})\end{array}$} & \multirow{2}{*}{$\begin{array}{c}\text { Fiber } \\
\text { nature }\end{array}$} & \multirow{2}{*}{$\begin{array}{c}\text { Aspect } \\
\text { ratio } \\
(\mathrm{L} / \mathrm{D})^{*}\end{array}$} \\
\hline & Name & (mmol) & & & \\
\hline B4CAP & $\mathrm{B} 4 \mathrm{CA}$ & $0.068(0.25)$ & $\begin{array}{c}0.245 \\
(1.1)\end{array}$ & Tube & $\sim 115$ \\
\hline B3CAP & B3CA & $0.069(0.33)$ & $\sim 35$ & Tube & $\sim 35$ \\
\hline B2CAP & B2CA & $0.083(0.50)$ & $\sim 20$ & Tube & $\sim 20$ \\
\hline HDP (control) & $\mathrm{HCl}$ & $0.036(1.0)$ & & Agglomerate & -- \\
\hline
\end{tabular}

*'L/D' length/diameter 


\section{Synthesis of HCl doped polyaniline (HDP)}

$\mathrm{HCl}$ doped polyaniline (HDP) was synthesized according to same procedure as previous. Hydrochloric acid $1.5 \mu \mathrm{L}(1.2 \mathrm{mmol}, 12 \mathrm{~N} \mathrm{HCl})$ added to $15 \mathrm{~mL}$ of water with stirring. Aniline $\left(100 \mu \mathrm{L}\left(1.02 \mathrm{~g} / \mathrm{cm}^{3}, 1.1 \mathrm{mmol}\right)\right.$ was added and stirring additional $30 \mathrm{~min}$. After cooling the mixture temperature to $10{ }^{\circ} \mathrm{C}$ an aqueous solution of APS added with stirring. Now reaction mixture kept in $0-5{ }^{\circ} \mathrm{C}$ for $18 \mathrm{~h}$. After that deep green colour precipitate wash with water and methanol several times. At last product dried in vacuum oven to get powdered HDP. 


\section{Synthesis of N,N'-Bis (4-benzosulfonic acid)perylene-3,4,9,10-tetracarboxylbisimide}

(PRSA)

\section{Materials}

Perylenetetracarboxylic acid-3,4,9,10-dianhydride purchased from Sigma Aldrich without further purification. Sulfanilic acid, Zinc acetate, Imidazole were supply Merck chemicals, India.

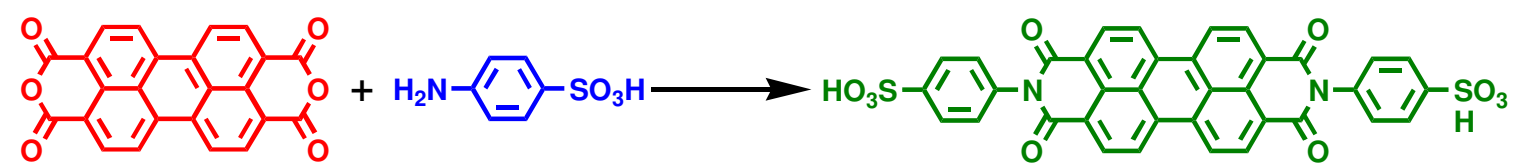

Scheme: Schematic representation of N, N'-Bis (4-benzosulfonic acid)perylene-3,4,9,10tetracarboxylbisimide (PRSA)

\section{Procedure}

Perylene tetracarboxylic acid-3,4,9,10-dianhydride is synthesized according to our previous report. ${ }^{\mathrm{S} 1, \mathrm{~S} 2}$ Perylene tetracarboxylic acid-3,4,9,10-dianhydride (1 g, $\left.2.54 \mathrm{mmol}\right)$, sulfanilic acid (1.3 g, $7.62 \mathrm{mmol}), 350 \mathrm{mg}$ of zinc acetate $(2.2 \mathrm{mmol})$, and $12 \mathrm{~g}$ of imidazole were taken in a two neck round-bottom flask. The reaction mixture was refluxed at $180{ }^{\circ} \mathrm{C}$ for $6 \mathrm{~h}$ in $\mathrm{N}_{2}$ atmosphere. After being cooled at room temperature, it was added to $50 \mathrm{~mL}$ of ethanol. The precipitate was collected by filtration, and after being dried in vacuum it afforded $1.68 \mathrm{~g}$ (93.8\% yield) of the product, 1, N, N0 -bis- (4-benzosulfonic acid) perylene-3,4,9,10tetracarboxylbisimide. 
TGA study of B4CAP matrix

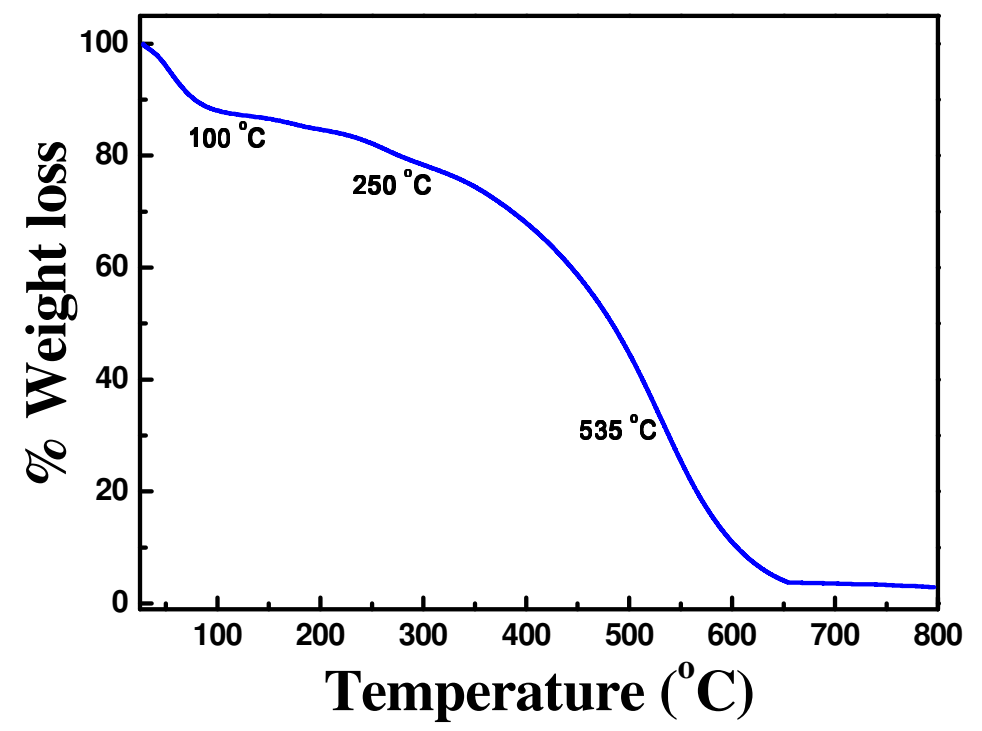

Figure S1: TGA study of B4CAP matrix under $\mathrm{N}_{2}$ atmosphere. 

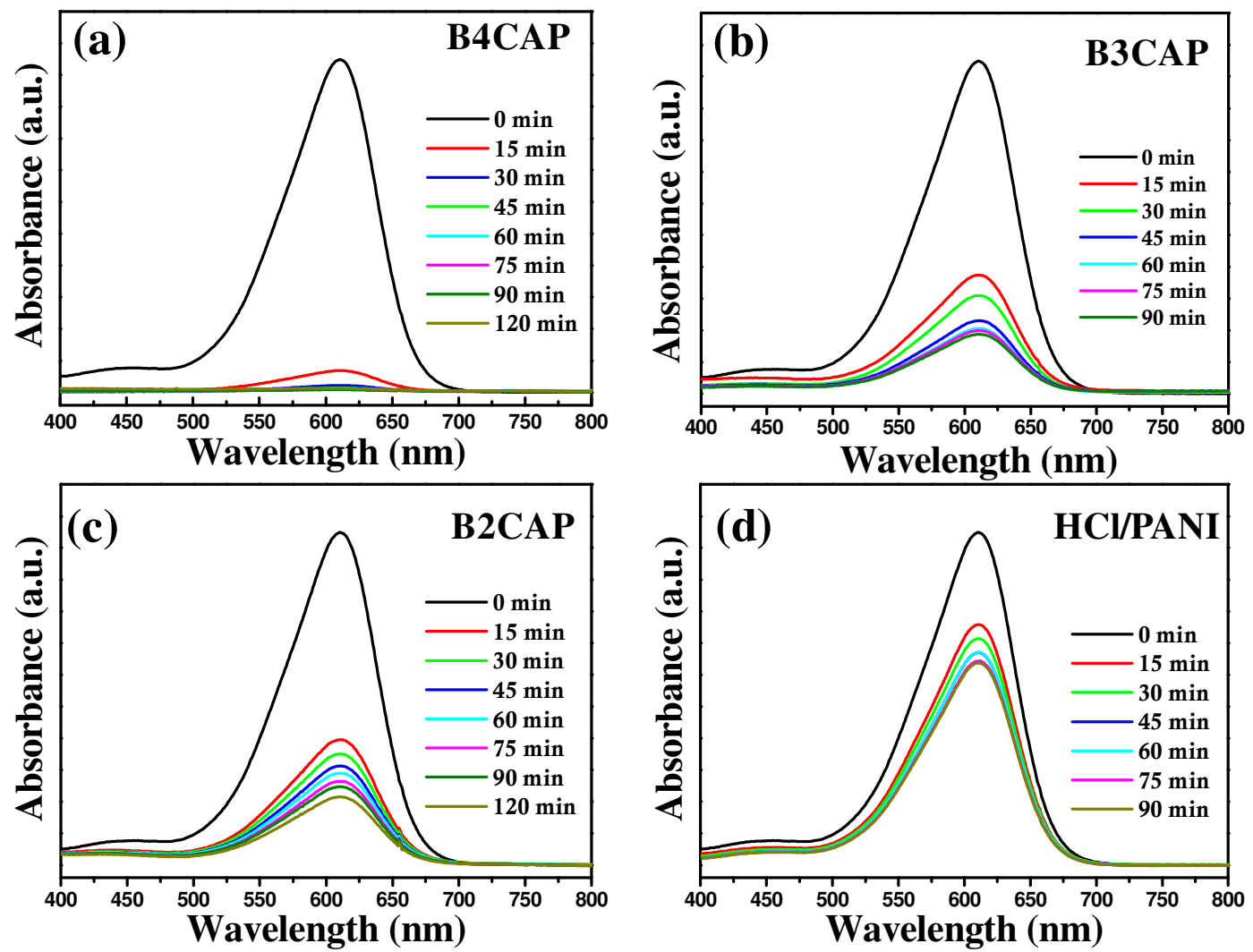

Figure S2: UV-Vis spectra of IC dye (model dye) adsorption study for (a) B4CAP, (b) B3CAP, (c) B2CAP and (d) HCl/PANI (control) matrix at room temperature. 
FESEM and TEM image of Polyaniline matrix
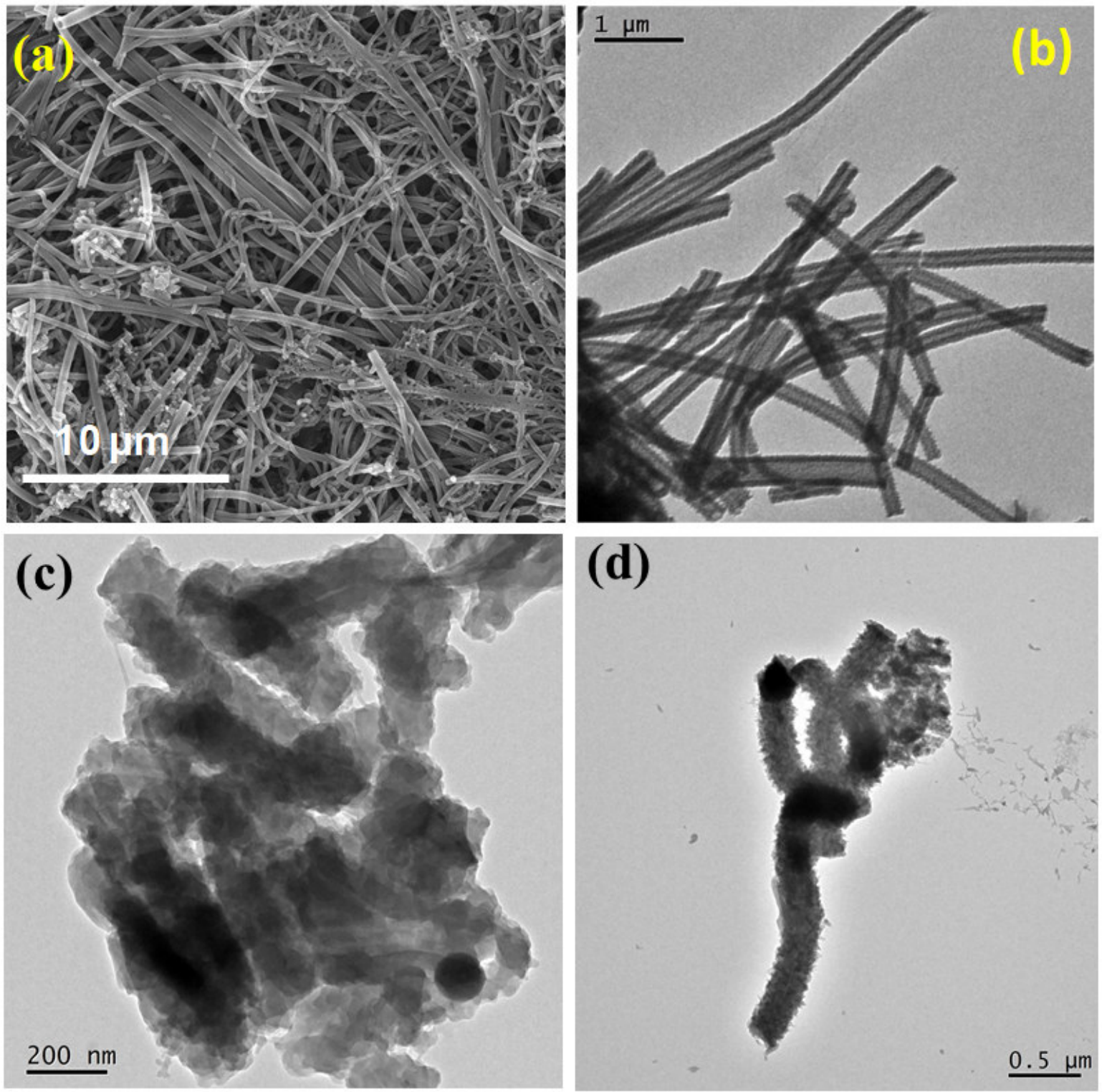

(d)

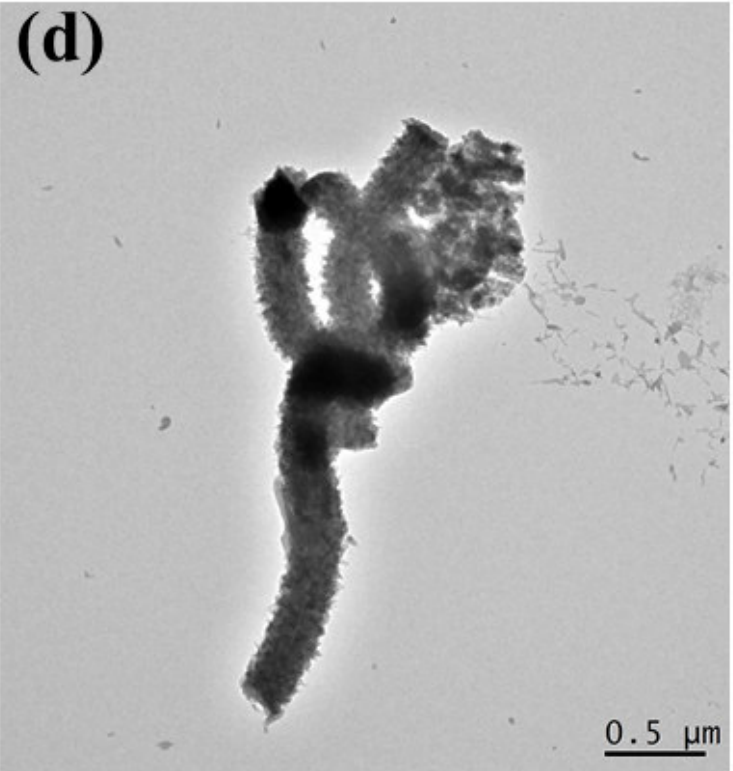

Figure S3 (a) Bulk state FESEM image of B4CAP matrix with fiber length 30 $\mu \mathrm{m}$ and diameter 260 nm; (b) Low magnified TEM images of B4CAP fibers are shows tube like in nature. (c) B3CAP and (d) B2CAP fibers. 
BET study of polymers

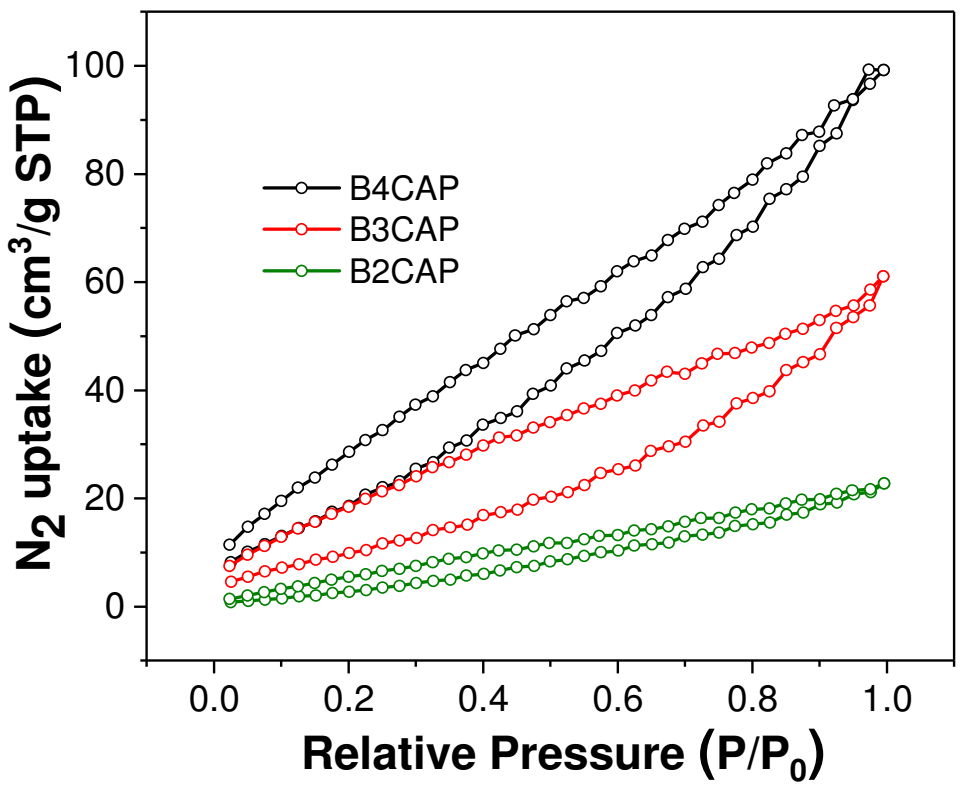

Figure S4: BET adsorption isotherms of PANI matrix. 
MB and CV dye adsorption study by B4CAP matrix
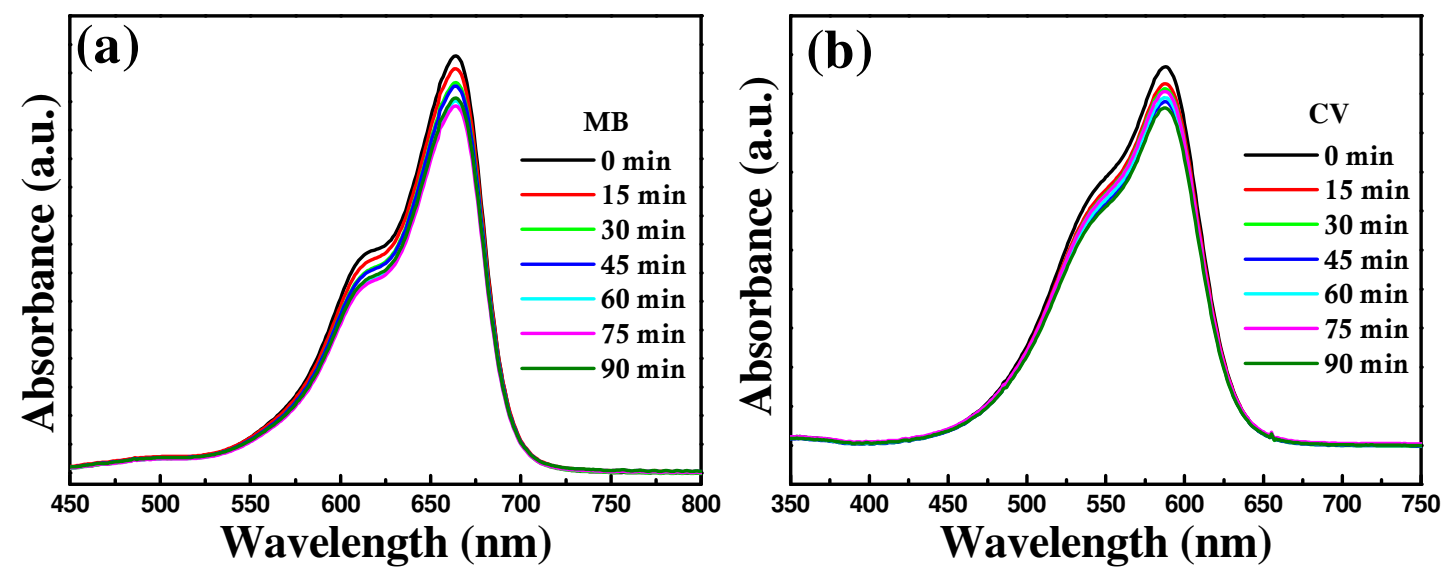

(c)<smiles>CN(C)c1ccc2nc3ccc(=[N+](C)C)cc-3sc2c1</smiles><smiles>CN(C)c1ccc(C(=C2C=CC(=[N+](C)C)C=C2)c2ccc(N(C)C)cc2)cc1</smiles>

Figure S5: UV-Vis spectra of (a) Methylene Blue dye, (b) Crystal Violate dye (as cationic dye) molecule by B4CAP matrix with different times at room temperature; chemical structure of (c) Methylene Blue dye (d) Crystal Violate dye. 
(a)<smiles>Cc1ccc(Nc2ccc(Nc3ccc(N=C4C=CC(=NC5CCCCC5)C=C4)cc3)cc2)cc1</smiles>

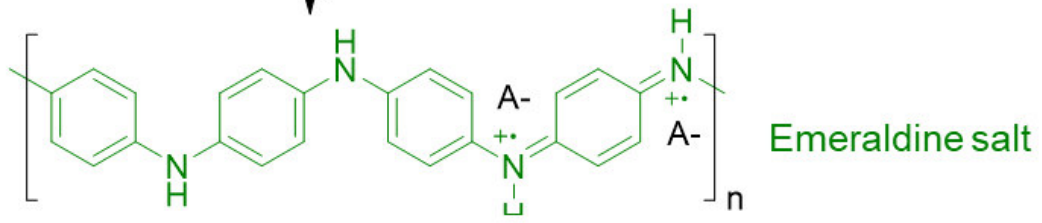
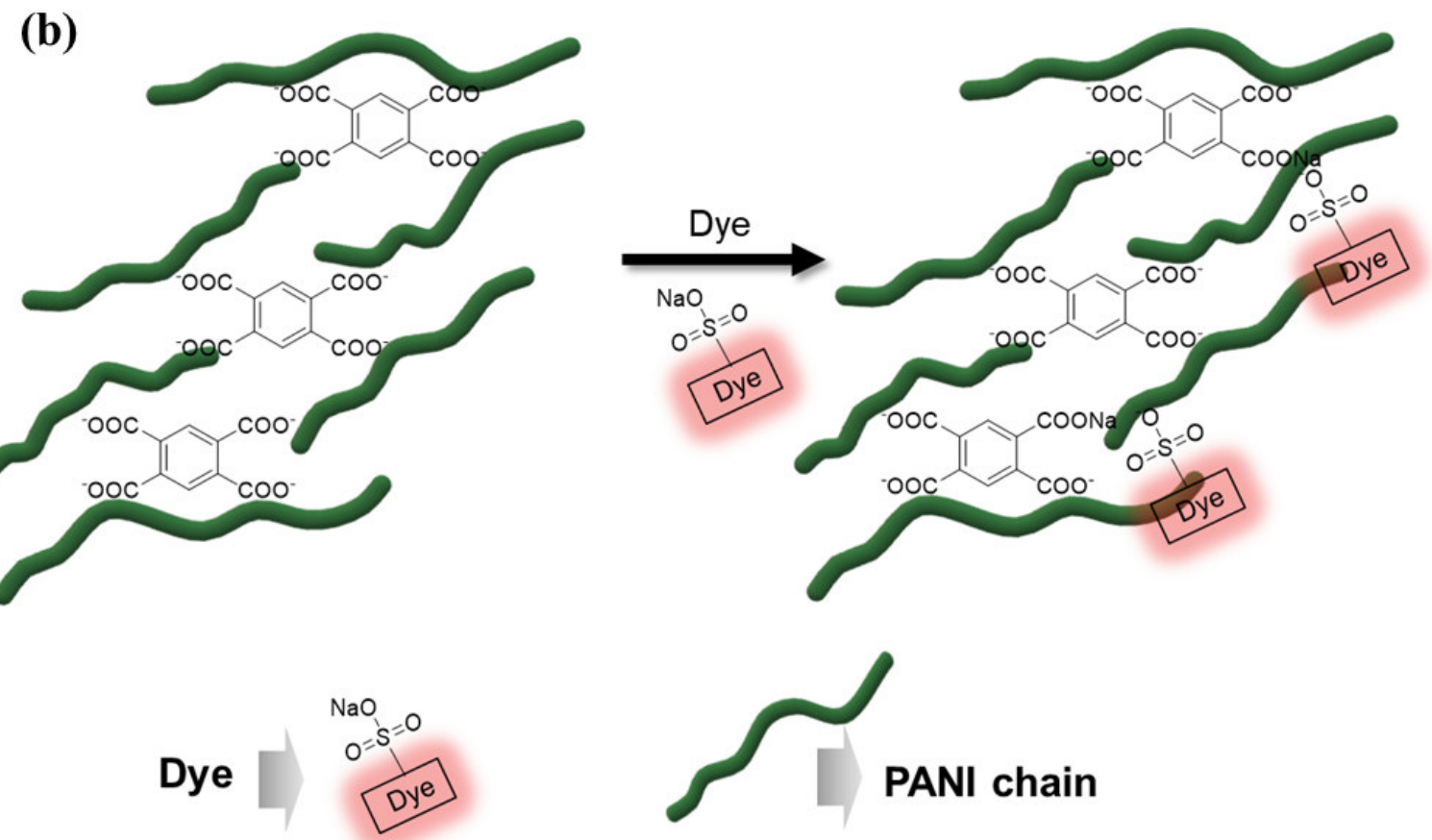

Figure S6: (a) Transformation of polyaniline chains form by acid base treatment; (b) Mechanism of adsorption of sulfonated dye on the surface of emeraldine salt form of PANI chains. Dye adsorption is possibly governed by the electrostatic interaction between the positively charged backbone of PANI emeraldine salt and sulfonic acid functional group over the same of the carboxylic acid functional group and imine of polyaniline chain. 


\section{Effect of pH on dye adsorption}

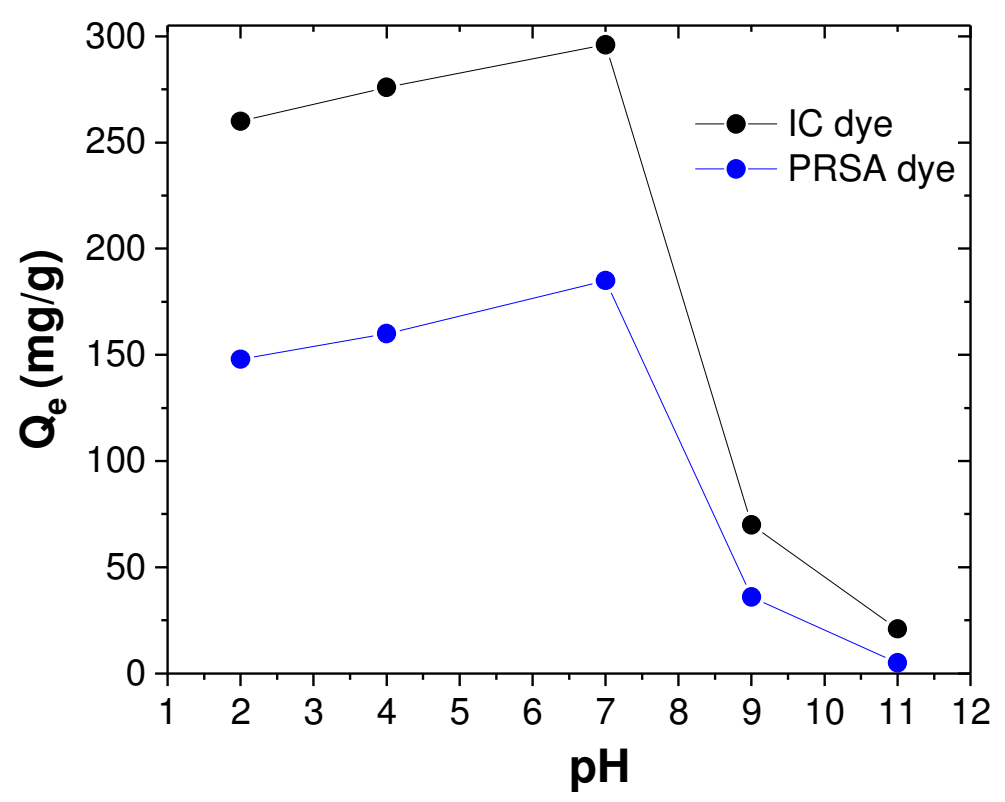

Figure S7: The Effect of $\mathrm{pH}$ of dye adsorption on PANI surface. If the $\mathrm{pH}$ of the medium is increased, PANI chains transform to emeraldine base form that may not interact with the negatively charge sulfonated dye molecule. As a result, adsorption will be decreased rapidly. Again to lowering the $\mathrm{pH}$ (below $\mathrm{pH}$ 5), PANI becomes emeraldine salt form and dye molecule will be protonated. Therefore at low $\mathrm{pH}$, lack of electrostatic interaction between dye molecule and PANI will be decreased the adsorption capacity. 

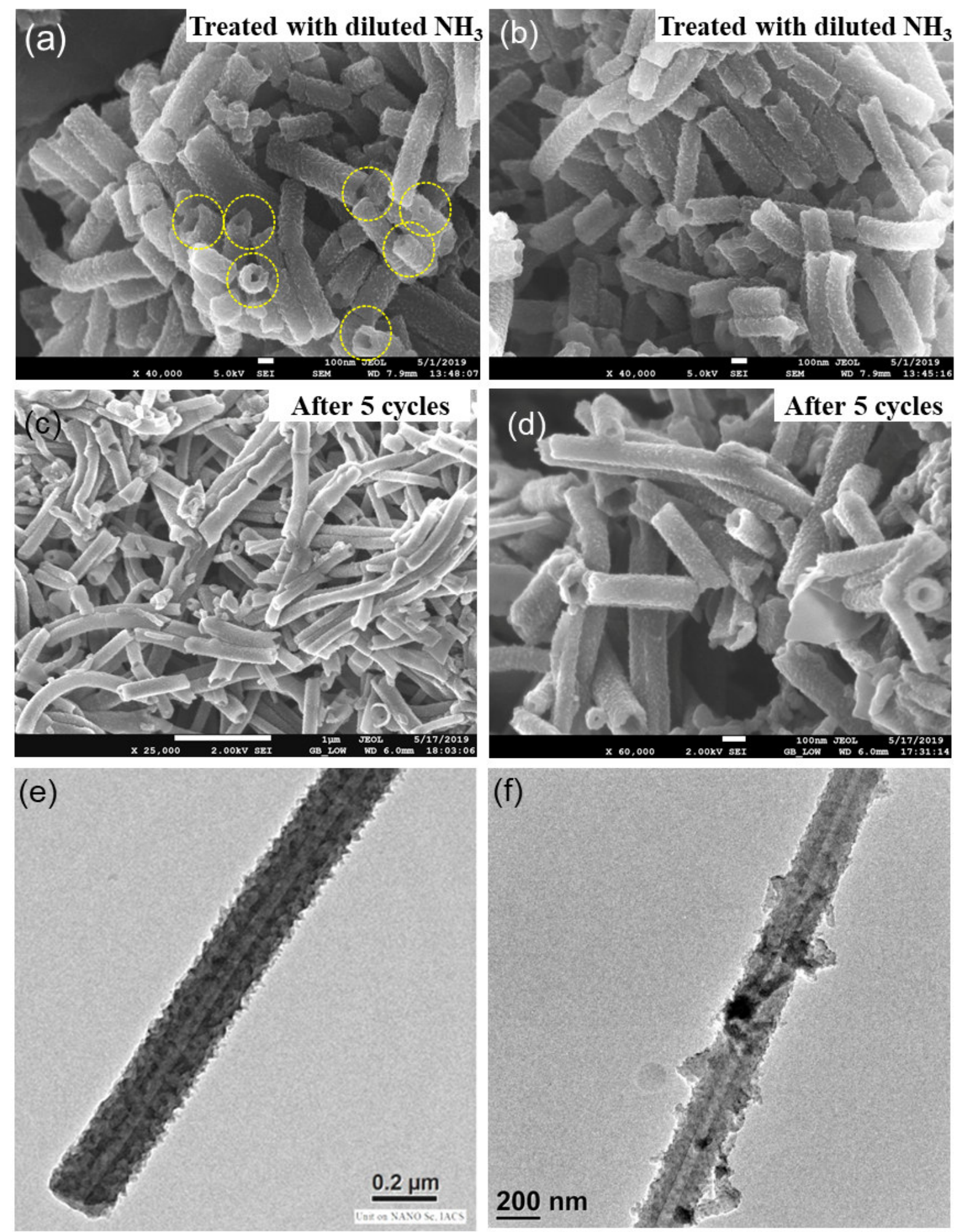

Figure S8 The morophology of B4CAP nanotubes after treat with diluted $\mathrm{NH}_{3}(\mathrm{a}-\mathrm{b})$ and after 5 th cycle of dye adsorption (c-d) at room temperature. HRTEM image of B4CAP fiber (e) before dye adsorption and (f) after dye adsorption. Both cases fiber shows tube like in nature. 
Table S2: Comparison with previously reported work

\begin{tabular}{|c|c|c|c|}
\hline Absorbents & Dyes $^{\#}$ & $\begin{array}{l}\text { Maximum absorbed } \\
\text { capacity }(\mathrm{mg} / \mathrm{g})\end{array}$ & References \\
\hline $\begin{array}{l}\text { Kapok fiber oriented } \\
\text { polyaniline }\end{array}$ & CR, OG-II, OG & $40.82,188.7,192.3$ & S3 \\
\hline Polyaniline $/ \alpha-\mathrm{ZrP}$ & MO & 377.46 & S4 \\
\hline Polyaniline/ & MO & $\sim 65$ & S5 \\
\hline \multicolumn{4}{|l|}{ Mesoporous Silica } \\
\hline \multirow[t]{3}{*}{ PTSA/PANI \& CSA/PANI } & OG & $342 \& 400$ & S6 \\
\hline & AG & $95 \& 151$ & \\
\hline & $\mathrm{CBB}$ & $207 \& 231$ & \\
\hline $\begin{array}{l}\text { Polyaniline-iron oxide } \\
\text { nanocomposites }\end{array}$ & $\mathrm{Rh}-\mathrm{B}$ & 100 & S7 \\
\hline $\mathrm{PANI} / \mathrm{HCl}$ & OG, AG, CBB, RBBR & $175,129,100,56$ & S8 \\
\hline $\begin{array}{l}\text { Polyaniline/Iron Oxide } \\
\text { Composite }\end{array}$ & $\mathrm{AB} 10 \mathrm{~B}$ & 56 & S9 \\
\hline $\begin{array}{l}\text { Aromatic carboxylic } \\
\text { acid/PANI }\end{array}$ & $\begin{array}{c}\text { IC, MO, CR, EBT, } \\
\text { PRSA, }\end{array}$ & $300,285,194,288,192$ & This work \\
\hline
\end{tabular}

\#Dyes: CR: Congo red, OG-II: Orange II; OG: Orange G; MO: methyl orange; RBBR:

Remazol Brilliant Blue R; CBB: Coomassie Brilliant Blue R-250; AG: Alizarine Cyanine

Green, AB 10B: Amido black 10B, IC: Indigo carmine, MO: Methyl orange, CR: Congo red, EBT: Eriochrome Black T, 


\section{References}

S1. Chakraborty, C.; Dana, K.; Malik, S., Intercalation of Perylenediimide Dye into LDH Clays: Enhancement of Photostability. J. Phys. Chem. C 2010, 115, 1996-2004.

S2. Rana, U.; Paul, N. D.; Mondal, S.; Chakraborty, C.; Malik, S., Water Soluble Polyaniline Coated Electrode: A Simple and Nimble Electrochemical Approach for Ascorbic Acid Detection. Synt. Met 2014, 192, 43-49.

S3. Zheng, Y.; Liu, Y.; Wang, A., Kapok Fiber Oriented Polyaniline for Removal of Sulfonated Dyes. Ind. Eng. Chem. Res. 2012, 51, 10079-10087.

S4. Wang, L.; Wu, X.-L.; Xu, W.-H.; Huang, X.-J.; Liu, J.-H.; Xu, A.-W., Stable Organic-Inorganic Hybrid of Polyaniline/A-Zirconium Phosphate for Efficient Removal of Organic Pollutants in Water Environment. ACS Appl. Mater. Interfaces 2012, 4, 2686-2692.

S5. Mahto, T. K.; Chandra, S.; Haldar, C.; Sahu, S. K., Kinetic and Thermodynamic Study of Polyaniline Functionalized Magnetic Mesoporous Silica for Magnetic Field Guided Dye Adsorption. RSC Adv., 2015, 5, 47909-47919.

S6. Mahanta, D.; Madras, G.; Radhakrishnan, S.; Patil, S., Adsorption and Desorption Kinetics of Anionic Dyes on Doped Polyaniline. J. Phys. Chem. B 2009, 113, 22932299.

S7. Dutt, S.; Vats, T.; Siril, P. F., Synthesis of Polyaniline-Magnetite Nanocomposites using Swollen Liquid Crystal Templates for Magnetically Separable Dye Adsorbent Applications. New J. Chem., 2018,42, 5709-5719.

S8. Mahanta, D.; Madras, G.; Radhakrishnan, S.; Patil, S., Adsorption of Sulfonated Dyes by Polyaniline Emeraldine Salt and Its Kinetics. J. Phys. Chem. B 2008, 112, 1015310157.

S9. Ahmad, R.;Kumar, R., Conducting Polyaniline/Iron Oxide Composite: A Novel Adsorbent for the Removal of Amido Black 10B. J. Chem. Eng. Data 2010, 55, 3489-3493. 